\title{
Ulcerated calcification of the interventricular septum causing Transient Ischemic Attacks: Case Report
}

\author{
Matthew Panagiotou*1, Kostas Markakis ${ }^{1}$, Nikolaos Mourtzis', \\ Stella Economidis ${ }^{1}$, James Crockett ${ }^{1}$ and Efstratios N Koletsis ${ }^{2}$
}

Address: ${ }^{1}$ Department of Cardiac Surgery, Athens Medical Center, Athens, Greece and ${ }^{2}$ Cardiothoracic Surgery Department, University of Patras, Greece

Email: Matthew Panagiotou* - mspanag@otenet.gr; Kostas Markakis - mmarakis@otenet.gr; Nikolaos Mourtzis - ekoletsis@hotmail.com; Stella Economidis - ekoletsis@hotmail.com; James Crockett - fccp_perfusionist@yahoo.co.uk; Efstratios N Koletsis - ekoletsis@hotmail.com

${ }^{*}$ Corresponding author

Published: 17 April 2007

Journal of Cardiothoracic Surgery 2007, 2:19 doi:10.1 186/1749-8090-2-19

Received: 16 February 2007

Accepted: 17 April 2007

This article is available from: http://www.cardiothoracicsurgery.org/content/2/1/19

(c) 2007 Panagiotou et al; licensee BioMed Central Ltd.

This is an Open Access article distributed under the terms of the Creative Commons Attribution License (http://creativecommons.org/licenses/by/2.0), which permits unrestricted use, distribution, and reproduction in any medium, provided the original work is properly cited.

\begin{abstract}
Background: Calcific deposits are frequently observed at sites of healed myocardial infarcts. Grossly visible calcification of myocardial infarcts and calcified intracavitary cardiac thrombi are less common but recently are becoming more frequent findings during surgical ventricular restoration procedures.
\end{abstract}

Case Presentation: A 64 years old male diabetic patient experienced two episodes of transient ischemic attacks during the last six months. During the diagnostic work up he was found to have triple vessel coronary artery disease with mild left ventricular dysfunction, akinesia of the anteriorapical wall and hypokinesia of the inferior wall. He was referred to our department for coronary artery bypass grafting. He underwent elective triple coronary artery bypass and a ventricular restoration procedure due to apical wall thinning. The inspection of the left ventricle revealed an ulcerated round shape calcification of the interventricular septum with a crater filled with clot. We resected the above lesion and covered the damaged area with the septal Dacron patch of the modified linear closure. The patient was discharged from the hospital on the I Ith postoperative day and has been doing well 6 months later, with improvement in both ventricular function and clinical status.

Conclusion: The exploration of the left ventricular cavity reveals interesting phases of the postinfarction healing process. The suspicion of left ventricular thrombosis in patients with ventricular asynergy justifies a ventricular exploration during coronary artery bypass surgery.

\section{Background}

Calcific deposits are frequently observed in human hearts. They are most commonly found in epicardial coronaries, mitral and aortic annular regions, apices of papillary muscles and at sites of healed myocardial infarcts [1]. Grossly visible calcification of myocardial infarcts, and calcified intracavitary cardiac thrombi, are becoming more frequent findings during surgical ventricular restoration procedures $[2,3]$. 


\section{Case report}

A 64 years old male diabetic patient with coronary artery disease and a history of myocardial infarction had recently experienced two episodes of transient ischemic attacks. The presumed diagnosis was cerebral embolism since an intracranial hemorrhage was excluded and there was no detected ipsilateral carotid stenosis. The patient was in NYHA class III, with no angina. Thallium-201 myocardial scintigraphy showed a combination of scar and viable myocardium in the territory of the occluded left anterior descending.

On coronary angiography he was found to have triple vessel disease, with total occlusion of the left anterior descending branch and of the right coronary artery. Left ventriculography revealed left ventricular dysfunction with a LVEF of 35\%, akinesia of the anterior-apical wall and hypokinesia of the inferior wall. He was referred to our department for coronary artery bypass grafting.

The operation was performed with the aid of cardiopulmonary bypass, moderate hypothermia and intermittent combined (retro and antegrade) cold blood cardioplegia. Intraoperatively the apical walls were found to be thin and scared and collapsed with ventricular venting.

We performed a triple coronary artery bypass with a left internal mammary artery to the intermediate artery (since it was the best target vessel) and two saphenous vein grafts to the obtuse marginal and the left anterior descending. The latter was endarterectomised due to chronic occlusion. Despite the fact that the patient had no absolute indication for a ventricular restoration (SVR) procedure, the extent of the damaged apical wall found intraoperatively and the history of the Transient Ischemic Attacks made us perform a ventriculotomy and an "anti-remodeling" procedure. After the ventriculotomy, inspection of the left ventricular cavity revealed a "round - shaped" calcification of the peripheral interventricular septum (diameter of $5 \mathrm{~cm}$ ) with a central crater filled with clot (Figure $1)$.

We performed a resection of the found lesion together with the surrounding damaged endocardium (endocardiectomy) (Figure 2).

The area of the endocardiectomy together with the infracted peripheral septum was covered with a Dacron patch. Consequently this septal patch was incorporated in the linear closure of the anterior-apical ventriculotomy [4].

Postoperative recovery was uneventful. He was discharged from the hospital on the $11^{\text {th }}$ postoperative day and is doing well 6 months later, with improvement in both ventricular function (LVEF 45\%) and clinical status (NYHA class I).

\section{Discussion}

Left ventricular thrombus formation may occur in the early course after acute anterior myocardial infarction. Delayed thrombus formation is always associated with wall motion deterioration. Oral anticoagulant therapy is strongly recommended in these patients and associated with thrombus resolution and decrease of embolic events. Some times persistent LV mural thrombi may become encapsulated by thickened and calcified endocardium [5].

The inspection of the LV cavity performed during SVR procedures, reveals different stages of the post-infarction ventricular healing process, previously less well recognized.

The accepted indication for an SVR procedure according to the experience is a $>35 \%$ asynergy of the left ventricular perimeter [6]. In cases with less extent of apical involvement but with significant wall thinning, a 'prophylactic' anti - remodeling muscle procedure is common practice [7]. Some surgeons are performing this procedure without even a ventriculotomy, by stitching 'blindly' the ventricular apex from outside. They define such a procedure as a minimally invasive one or an 'off-pump' ventricular restoration. The later procedure must be an absolute contraindication in cases with suspected ventricular thrombi, which in the author's experience are not rare even in patients on anticoagulation treatment.

\section{Conclusion}

Inspection of the left ventricular cavity in ischemic cardiomyopathy patients with apical asynergy reveals interesting phases of the post-infarction healing process. Utilizing a lower decision threshold for a ventriculotomy and surgical ventricular restoration surgery can be advantageous especially in coronary patients with segmental asynergy and suspected ventricular thrombi.

\section{Abbreviations}

SVR: Surgical Ventricular Restoration Procedure

\section{LV: Left Ventricular}

LVEF: Left Ventricular Ejection Fraction

\section{Competing interests}

The author(s) declare that they have no competing interests.

\section{Acknowledgements}

Written consent was obtained from patient's relative for publication of study. 


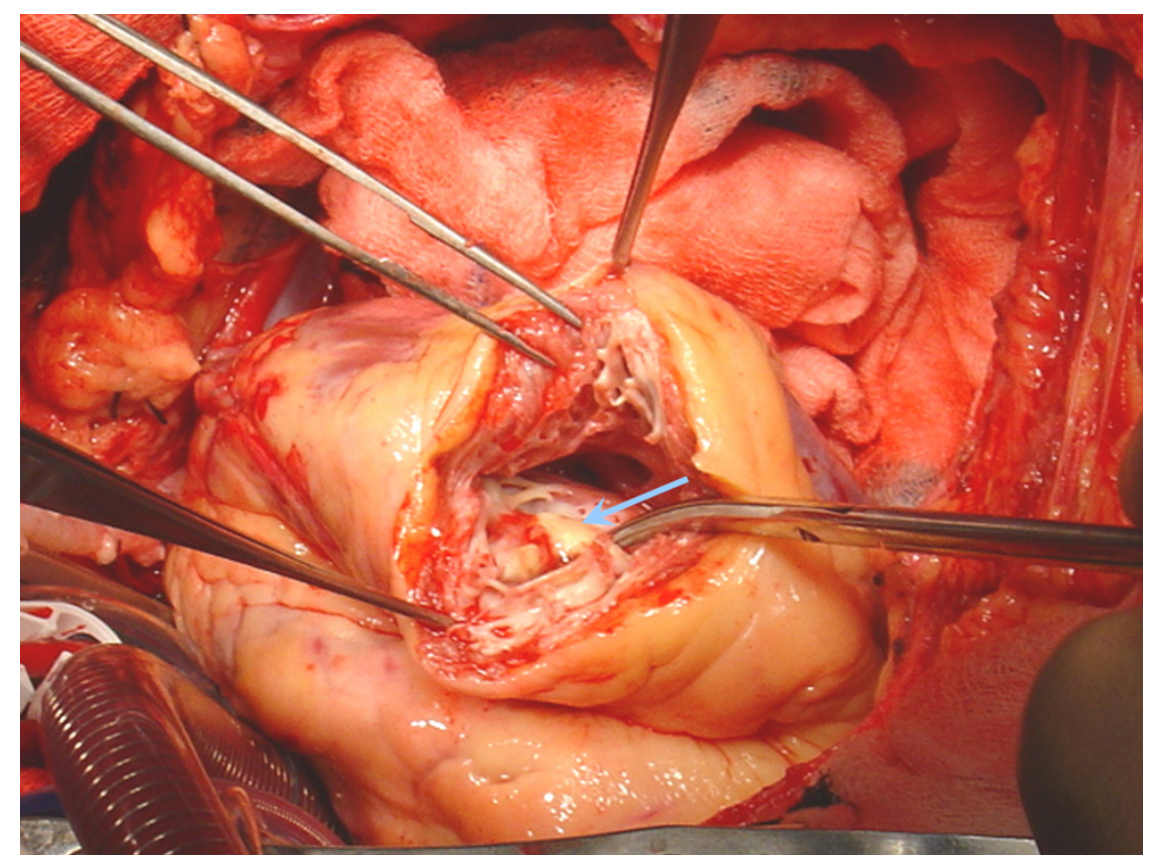

Figure I

Intraoperative picture after opening the left ventricle. A round - shaped calcification (diameter of $5 \mathrm{~cm}$ ) with a central $\mathrm{crater}$ (pale blue arrow) filled with clot was clearly evident at the peripheral interventricular septum.

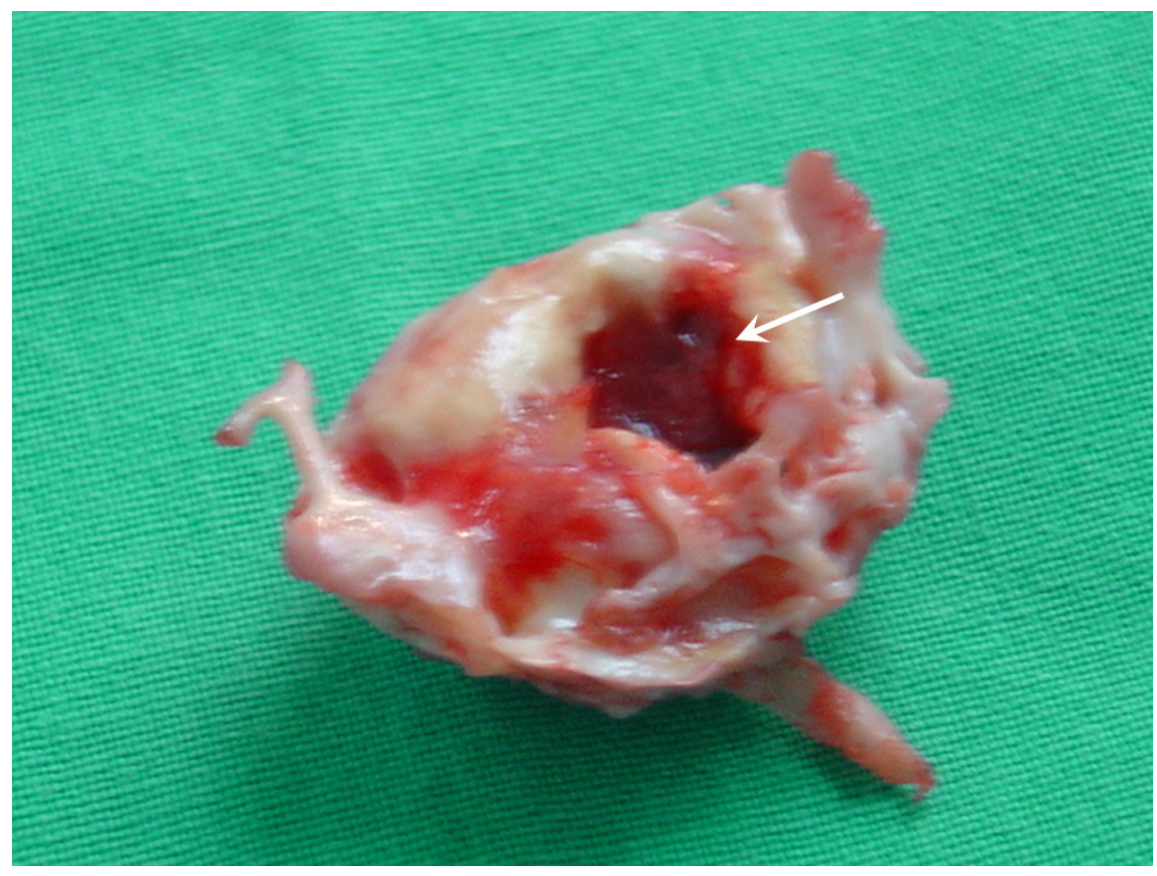

Figure 2

The round shaped calcification specimen with a central crater (white arrow) filled with clot. 


\section{References}

I. Roberts W, Kaufman R: Calcification of myocardial infarcts. Am J Cadiol 1987, 60:28-32.

2. Morales C, Bernal JM, Rabasa JM, Gutierez F, Val F, Revuelta JM: The fine art of nature. J Thorac Cardiovasc Surg 1997, I I 4:49|-2.

3. Greaves SC, Zhi G, Lee RT, Solomon SD, MacFadyen J, Rapaport E, Menapace FJ, Rouleau JL, Pfeffer MA: Incidence and natural history of left ventricular thrombus following anterior wall acute myocardial infarction. Am J Cardiol 1997, 80:442-8.

4. Micklebororough LL, Carson S, Ivanov J: Repair of dyskinetic or akinetic left ventricular aneurysm: Results obtained with a modified linear closure. J Thorac Cardiovasc Surg 200I, | 2 1:675-682.

5. Auer J, Berent R, Lassnig E, Weber T, Eber B: Calcified left ventricular thrombus in a patient after myocardial infarction. Int J Cardiol 2002, 82: 185-186.

6. Menicanti L, Di Donato M: The Dor procedure: What has changed after fifteen years of clinical practise. J Thorac Cardiovasc Surg 2002, I 24:886-90.

7. De Bonis M, Alfieri O: Surgery Insight: surgical methods to reverse left ventricular remodelling. Nat Clin Pract Cardiovasc Med 2006, 3:507-13.

Publish with Bio Med Central and every scientist can read your work free of charge

"BioMed Central will be the most significant development for disseminating the results of biomedical research in our lifetime. "

Sir Paul Nurse, Cancer Research UK

Your research papers will be:

- available free of charge to the entire biomedical community

- peer reviewed and published immediately upon acceptance

- cited in PubMed and archived on PubMed Central

- yours - you keep the copyright

Submit your manuscript here:

http://www.biomedcentral.com/info/publishing_adv.asp 